\title{
"MADE IN HEAVEN": POLITICS, ART, AND PORNOGRAPHY
}

\section{Kirsten Strom}

\section{Defining Barriers: the Conundrum of Art and Pornography}

In reviewing Jeff Koons' controversial Banality show for The Nation in 1989, Arthur C. Danto commented that it seemed to have revived a question that he had thought long dead in the artworld: "But, is it art?" (788-9). The show featured, among other things, a statue of Michael Jackson with his pet monkey Bubbles, the figure of a topless blond woman caressing a Pink Panther doll, and a bust of St. John the Baptist cradling a pig and a penguin in his arms, all in larger-than-life-size porcelain. Two years later Koons unveiled his next major exhibition, and as the critical response suggests, Made in Heaven seemed to force once again the question: "But, is it art?" The implication of such a question is, of course, that if the "it" in dispute is not art, then it must be something else, and in the case of Made in Heaven that something else was pornography, a category which-like art-eludes precise definition.

Typically, questions about whether a work is or is not a work of art have been based on the physical nature of the work: is Marcel Duchamp's unaltered snow shovel a work of art?; is Robert Rauchenberg's "blank" canvas art?; can Vito Aconci's street actions be considered art? Conversely, there tends to be little doubt over whether objects that fall comfortably within the parameters of painting and sculpture are art, particularly when they are representational and especially when they are placed within the context of a museum or gallery, as the Made in Heaven objects were. To a certain degree these works do confound the categories of "painting" and "sculpture," in that the "paintings" were photographic images printed with oil-based inks onto canvases, and the wood and glass sculptures were executed (in media traditionally associated with the decorative arts) by unnamed craftspeople and not by Koons himself. Yet the issues apparently raised by these works were not "but, is it painting?," or "is it really sculpture?" Indeed the controversial nature of the works was based not on their form, but on their content: the unabashed performance of sexual acts.

Specifically, the images portray Koons and his wife Ilona Staller (a.k.a. "Cicciolina") engaged in a variety of sexual acts and scenes typical of porno- 
graphic representation: several positions of intercourse, oral sex, post-coital ejaculation, and so on. Typically, Koons is completely nude, while Staller dons a somewhat cliché array of spiked heels and lacy and/or leather lingerie. With few exceptions, she is dressed all in white and crowned with a wreath of flowers, making her strangely reminiscent of a 60's flower child. Most of the canvases depict scenes taking place in front of painted or otherwise artificially constructed sets, although a few take place in "Ilona's home," and another, entitled Manet, depicts the couple engaged in cunnilingus in a grassy landscape, a reference no doubt to the painter's famous Dejeuner sur l'herbe.

Throughout the images there is a sense of artifice and performance. Indeed one would have to be particularly naive-or "perverse"-to believe that this is a "real" window into the private sexual life of the couple. They are "betrayed" not only by the artificial backdrops, but by their own expressions as well. In most cases, Koons appears overly sincere as he gazes tenderly at his wife, while Staller's stock expression of ecstasy, virtually identical in nearly all the images, suggests that she is indeed "faking it." Finally, certain images depict Koons, and occasionally Staller, smiling knowingly and directly at the viewer, destroying altogether any hope for a classical illusion of "reality."

In addition to the paintings, the show's other components featuring Koons and Staller included a larger-than-life-size polychromed wood sculpture based on one of the paintings, two heroicizing marble portrait busts-one of Koons alone and the other of the couple embracing-and a series of glass figurines, each tinted a different color, and each portraying the couple in a different sexual position. In their titles, each of these small works claims reference to what Foucault has referred to as the ars erotica tradition of the Kama Sutra: Position Three (Kama Sutra), Jeff Eating Ilona (Kama Sutra), and so on. Scattered throughout the show were its various non-sexual components-sculptures depicting putti figures, abundant bouquets of flowers, and smiling dogs of various popular breeds.

In response to the primary question which seemed to be begged by Made in Heaven-is it art? - most critics commenting on the show have asserted that it is. Indeed, they provide a fairly diverse and somewhat telling array of theoretical explanations as to why the show does not constitute pornography. For Jim Lewis, "[the work is] not...pornographic...because an art work becomes prurient only when it ceases to be a representation of desire and instead become the impetus for it." He goes on to state that "These works would be very much diminished if they provided occasions for arousal. They don't, and they're not intended to" (16). According to John Caldwell, "A curious aspect of Koons's new paintings is that they are not pornographic, even though they are explicit depictions of sexual activity. One might attribute this paradox to personal taste, had it not been remarked on over and over by visitors to the exhibition in which they were first shown. Probably the reason for this is that they are too real." $\mathrm{He}$ then elaborates by invoking Susan Sontag's 1969 essay on pornography in which she suggests, as Caldwell paraphrases, "that the characters in a pornographic novel must be fairly generic figures in order for us to project our erotic desires onto them" (14). Even Annie Sprinkle, who reviewed the show in Arts Maga- 
zine wrote, "Take it from me, a pornographer for 20 years, Made in Heaven is anything but pornographic. It's art. In fact, it is positively clean and pristine art. A sort of Lutheran preoccupation with hygiene pervades even the most ordinary things depicted here" (48). Finally, as reported by David Littlejohn, the Koons retrospective that opened at the San Francisco Museum of Modern Art in 1992, contained a placard posted at the entrance to the obscured and often overlooked gallery in which the Made in Heaven series was displayed, which "insisted," in Littlejohn's words "that these images are not pornographic because 'they do not invite the participation of the viewer,' [Littlejohn's emphasis] and because they show real, identifiable, nonfantasy people (who are, indeed, married)" (91).

Curiously, perhaps, none of the aforementioned writers seemed willing to entertain the possibility that a work could be a work of art and a work of pornography simultaneously. In other words, by affirming that a given sexually explicit work in question is indeed art, one does not undo the terms on which the question "is it art?" is based; that is, the assumption that the categories of art and pornography are mutually exclusive is itself affirmed. Thus pornography is "defined"-albeit circuitously—by its status as "not art."

Of course the mutually exclusive relationship between art and pornography has typically been conceived of as a hierarchical one, one in which pornography can be construed as mere "bad" or "low" art. Sexually explicit "high" art, also known as "erotica," by contrast supposedly possesses artistic and/or literary value that transcends its prurient interests. This does not necessitate, however, that these prurient interests are defeated all together. Interestingly, several commentators felt compelled in discussing Made in Heaven to assert that they were not aroused by the work, Littlejohn even referring to it as "the reverse of erotically arousing" (91). Thus the category of pornography would seem to come into play when a sexually explicit work fails to transcend its own explicitness with some sort of artistic and/or literary aesthetic "merit." Although Koons' commentators seemed to have avoided making this argument explicitly, as indeed the images are hardly more aesthetically remarkable than those of any glossy hard-core magazine, the argument for the transcendental nature of aesthetics often seems somehow implied in their comments, particularly in the remarks of Jim Lewis, who, as previously noted, commented that the works would be "very much diminished [emphasis added] if they provided occasions for arousal" - that is, if they did not manage to transcend their own content. Caldwell even indirectly managed to assign the images a kind of literary merit, suggesting that their "characters" are more "real," more developed, than those of mere pornography.

\section{Associations: The Loaded Personae of Jeff Koons and Ilona Staller}

Of course, the "characters" of Jeff Koons and Ilona Staller were "developed" not so much in the images comprising the Made in Heaven show, but in the international media, for by 1991 both were well established media stars, and thus, the images depicting them functioned to arouse a wide range of extradiagetic associations, some of which will briefly be considered. 
At age 25, Koons had achieved almost instant artworld notoriety when he exhibited a show called The New in 1980, which consisted almost exclusively of a variety of vacuum cleaners displayed in plexiglass cases. Five years later he caused a similar stir with a series of basketballs sustained in aquariums, shown as part of his Equilibrium series, which also displayed framed Nike posters of famous basketball players. His Statuary show of 1986 consisted of statuettes cast in stainless steel, including objects depicting Bob Hope and an inflatable plastic rabbit. Then in 1989, he gave new meaning to the word kitsch with his Banality show, which, as previously discussed, appropriated the tacky products of mass culture and monumentalized them in glossy porcelain.

Koons of course gained notoriety not only for the flagrant appropriations of schlock that his objects represented, but for his absurdly hyperbolic commentaries and his disingenuous manner as well. Indeed Koons is perhaps first and foremost a performance artist - or better still, a persona artist. While critical discussions of his work have typically centered around issues of capitalism, consumerism, commodity fetishization, and simulacrum theory, Koons himself has always discussed his own objects in peculiarly spiritual and/or metaphysical terms. According to Koons, the vacuum cleaners are "anthropomorphic...breathing machines," while the aquariums represent not only an "ultimate state of being," but "the beginning of artificial intelligence" as well. Of his general aims, he states that his work is designed to make the bourgeoisie feel good about themselves by providing a model of self-acceptance. Claiming that the artworld has disempowered itself through its own elitism, Koons asserts that he looks instead to the worlds of advertising and entertainment in order to learn to "communicate" as effectively as possible, seeming to mean somewhat euphemistically that he wishes to become a staple not only of the artworld, but of popular culture a well.

In a 1990 interview, Koons claimed that his two favorite artists were Michael Jackson and "Cicciolina" (Ilona Staller), both whom he admired for their readiness to do anything necessary to communicate (Audio Arts). Of the latter, he has said, "Ilona is one of the greatest artists in the world. She is a great communicator, a great liberator. Other artists use a paintbrush. Ilona uses her genitalia" (Taschen 142).

Indeed Staller, who married Koons in 1991, had had quite a career in "communication," and while critics generally cite only Koons as the sole author of the Made in Heaven series, Staller was at the very least an influence on, as well as a loaded presence within the work.

Throughout the 70's and 80's Staller became increasingly well known to the Italian public for her erotic performances in films and photographs, on stage, and even in a radio show, eventually gaining a widespread fame virtually unthinkable for an American porn star. Along with her manager, photographer Riccardo Schicchi, Staller began her own pornographic video production company, Diva Futura. Then in 1987, she expanded her professional repertoire once again when she was elected as a Deputy to the Italian Parliament on the Radical Party ticket. No one claims to understand precisely how this happened, but some have offered theories. Andrea Lee, for example, has suggested that the 
Italian voters "have become cynically fatalistic about their chances of influencing the political direction of their country," and as a result cast "protest ballots" (136). Mark Lilla, however, has attributed Staller's victory to the "energy and shrewdness" of Schicchi who "knew that the campaign was an ad man's dream," and "wrote a separate Cicciolina platform" emphasizing the liberalization of sex laws, while also advocating solar energy, animal rights, and so forth (15). Similarly, Diva Futura actress Moana has said, "The people who elected Cicciolina, in my opinion, thought she might be a new voice, might serve for something [sic]" (Lee 143). In any case, the Italian Radical Party is notorious for its love of inflammatory and/or subversive gestures and publicity stunts, which seems to have provided the impetus for her initial nomination.

(As both Lee and Lilla have attested, Staller's nomination and consequent election represented something of a crisis for feminists within the Radical Party, several of whom held a press conference protesting "the manipulation of Staller by the media" (Lee 139). According to Lilla, "There were some rumblings from feminists in the party. But no one could offer a reason not to nominate her. As. . Adele Faccio put it, 'If we defend homosexuals and transsexuals, why not porno stars?"' (15).)

Not surprisingly, Staller's election-and her consequent exploitation of diplomatic immunity in the form of public displays of nudity-attracted the attention of the international as well as the Italian presses, garnering such headlines as that appearing in People Weekly (6 July 87): "In a naked play for power, porn queen Cicciolina wins a seat in Italy's Parliament." Indeed by 1990, the Koons-Staller duo had gained enough mainstream press coverage and even popularity to be featured in popular American magazines such as Vogue and Vanity Fair (neither of which is known particularly for its features on artists or porn stars - or Parliamentarians for that matter.)

Like Koons, Staller is famed not only for her works, but for her persona as well, specifically as it is manifested in the "character" of Cicciolina, a name, meaning approximately "fleshy little pinchable one," that was given to her by Schicchi when he became her manager. Lee notes that Cicciolina, known among other things for spontaneously baring her breasts in public, has her own distinct voice, a "girlish flutter" different from Staller's "low-pitched" "normal" voice. Apart from the two voices, however, there would seem to be little to distinguish Cicciolina from Ilona Staller who, according to Lee, "makes appearances dressed like a hybrid of Gigi and Little Eva. . .clutching stuffed animals... [giving] curiously daffy flower-child speeches praising nature and free love" (134). Staller herself has remarked, "I love the stir I can create with my body....I adore it, I'd like to have all of them touch me. The personaggio Cicciolina is not really an act at all-she is an expression of the child within me, the child without shame" (Lee 141).

Koons has repeatedly described her in similar terms, praising her not only as a great communicator, but as a great liberator as well. By removing "guilt and shame" from her life, he has claimed, she has become the "eternal virgin": "She is totally pure" (Renton 111-2). 


\section{Koons, Femme Productions, and the Rhetoric of Sexual Healing}

The somewhat unlikely casting of Staller as the "eternal virgin," is, however, just the beginning of the rhetoric Koons had laid forth for the Made in Heaven show. He had in fact devised quite an elaborate rhetorical program that is both strangely consistent with his earlier rhetoric and perhaps even more strangely compatible, in several respects, with the platform advanced by selfproclaimed "feminist" porn star and producer Candida Royalle, founder of the Femme production company.

With his usual flair for the hyperbolic, Koons has said of the Made in Heaven show: "I went through moral conflict. I could not sleep for a long time in the preparation of my new work. I had to go the depths of my own sexuality, my own morality, to be able to remove fear, guilt and shame from myself. All of this has been removed for the viewer. So when the viewer sees it, they are in the realm of the Sacred Heart of Jesus" (Rosenblum 130). Similarly, he has described himself and Staller as "the contemporary Adam and Eve. I believe totally that I'm in the realm of the spiritual, now, with Ilona. Through our union, we're aligned once again with nature. I mean we've become God. That's the bottom line-we've become God" (140).

For some, Made in Heaven has proved difficult to assimilate into the larger body of Koons" work. Daniela Salvioni, for example, writes that the work "falters in a way that no other Koons work does" (24), while Mark Van Proyen has called it "Koons' waterloo" (19). Indeed, unlike the vast majority of images comprising Koons' previous work, those of Made in Heaven are created rather than appropriated, and at first glance, the subject matter looks to be considerably more risqué that the teddy-bears and inflatable rabbits of Koons' earlier work.

But there is an important link between Made in Heaven and the earlier work, and that link is popular culture. For whether or not the work actually is pornography, with its blunt, even "hard-core" depictions of sex acts, it is obviously related to pornographic imagery, and while pornography may be predominantly "behind the counter," it is still to be found on any given Main Street. It is part of our popular culture. Koons has always stressed that his art, by monumentalizing aspects of popular culture, expresses a desire to teach the bourgeoisie to "embrace their past," and to accept their middle class taste for knick-knacks, People Weekly, and K-Mart without shame. It would seem to follow then that Made in Heaven attempts to extend this form of acceptance without guilt or shame to pornography: "I demand the right to express my own sexuality," Koons has said (Taschen 126).

Koons, however, while seeming on the one hand to be endorsing the acceptance of popular culture's taste for pornography, denies, on the other hand, that his work is pornographic: "I'm not involved in pornography. . . Pornography is just performing a sexual act. It really has no interest for me. I'm interested in love, I' $m$ interested in reunion, I'm interested in the spiritual, to be able to show people that they can have impact, to achieve their desires" (112).

This of course brings us back to the "spiritual" aspirations of the work, and while Koons' flamboyance in discussing the subject may seem ironic and disin- 
genuous, others advocating a feminist and/or New Age reconceptualization, or a "re-vision" of pornography, to use Linda Williams' term, seem to advance similar sentiments. Candida Royalle, for example, has stated that her aims in founding the Femme label were to produce porn that had "integrity," that was "non-sexist" but was "life-enriching [emphasis added]." Koons similarly has said of Made in Heaven that "It's really. . .to let people have hope in their lives again, that they can achieve their goals and their desires. . to let them regain their self-confidence, to let them live their desire" (Renton 111).

Combating notions that pornography is both immoral and dangerous to women, Royalle has said, "I wanted to make films that made people feel good about their sexuality and about who they are as sexual beings." The problem for Royalle is that ours is a culture of "guilt and shame"-one of Koons' favorite expressions - that stigmatizes women in particular for their sexuality (23). Similarly, Femme performer Nina Hartley has said, "I really see my work as important for women. I think sex is a very valid area to explore on an artistic level and women need to reclaim that. We need to be less afraid of our sexuality" (Chapkis 36). In practice, this has meant that by comparison with (maleproduced) mainstream pornography, films produced by Femme have emphasized a greater contextualization of sex acts, with fewer "meat" and "money" shots, the emotional intimacy of sexual contact, mutual desire and consent, the use of real life lovers, and the ideal of metaphorical female self-discovery through an exploration of female sexuality.

Although Koons' work arguably lacks the emphasis on the particularly female experience of reclaiming sexuality, Made in Heaven, on other levels, seems in keeping with various Femme norms. For example, there is a heavy emphasis on intimacy and monogamy, and indeed Koons and Staller were a genuinely married couple. Secondly, in nearly all the images the bodies of both Koons and Staller are uncropped, emphasizing the "holistic" nature of their sexual experience. Other Femme-esque aspects of the work include the "romantic" backgrounds of many of the paintings, the frequent role-reversals in which Koons and Staller alternate in the role of "top," and while it may be difficult to assert that the very experienced Staller is discovering herself in the images, there does seem to be a special emphasis on her sexual pleasure. Finally, Koons has explained that his own nudity and Staller's lack thereof as an attempt to express his desire not to be exploitative of her and/or her body.

Apparently, charges of misogyny have been leveled against the show nonetheless, which seem to bear witness to the impact of anti-pornography feminism within the artworld. But as Salvioni has remarked, "Qualms about these works being degrading to women are not convincing, unless you believe that heterosexual sex is inherently masculinist. The sex positions are varied and pleasure seems to be enjoyed by both; Cicciolina does wear suggestive clothing, while Jeff is simply naked, but it is she who seems the more surefooted of the two" (25).

Furthermore, in reviewing Made in Heaven, Femme colleague Annie Sprinkle claims that she "instantly fell in love with the show." As is evident in many aspects of her work, Sprinkle has repeatedly revealed herself to be con- 
cerned with what she sees as the undervalued relationship between sexuality and spirituality: "What's really interesting is that in my community of prostitutes, people in pornography, sexual radicals, the really hard thing has been for me to come out as spiritual. That was the Big Taboo. A lot of my friends just do not want to know about tantra, they still think it's a passing phase" (Chapkis 89). Consequently, Sprinkle began a series of workshops entitled "Sluts and Goddesses," designed to liberate the sexual and the spiritual in its (female) participants. Rating Made in Heaven on the Slut and Goddess scale, Sprinkle passed it with flying colors: "one of the most revolutionary components of Made in Heaven is Staller herself. She appeals to that secret desire in many women to be not only a goddess but a slut. She wears crowns and garter belts. . . She contains contradictions, and she does it with charm and grace."

Sprinkle's praise for Staller, however, does not end there, as she remarks that "Koons has clearly been influenced by her generous spirit and creative genius. Ilona Staller is a special person-innocent, child-like, and uninhibited. Staller has no guilt or shame about her body, and it's rubbed off on Mr. Koons" (47). Indeed Staller seems something of a cross between Sprinkle herself and Brazilian "children's" performer Xuxa. As with Royalle and Sprinkle, when Staller speaks of liberating people from guilt and shame, one suspects that however naive or quixotic it may seem, she is in fact quite earnest and sincere. Koons, however, who comes on with the veneer of a used-car salesman, speaks of his similarly lofty but exaggerated intentions in a manner that suggests irony, parody, and cynicism.

Perhaps then it should come as no surprise that the marriage "made in heaven" had turned into an ugly and tabloidesque break-up and custody battle within three years. Staller, who took their two-year-old son Ludwig Maximilian Koons to live with her in Rome charged Koons with kidnapping when he brought the boy back to New York in spite of an Italian court ruling that Ludwig could not be taken out of the country. The ever savvy Koons, however, knowing both his audience and the power of the word "pornography," appealed to the American courts that Staller was raising their son among pornographers and using him to promote her own pornographic career "selling nude photographs of the boy shot by a pornographer [probably Schicchi]" (Arena). Scenes of three films featuring Staller's pornographic performances were screened at a hearing (at which Staller herself was not present), while Koons testified both that Staller had refused his request to convert to Protestantism, and that she would "do anything to dismantle cultural mores" ("Scenes" 39).

Koons eventually granted custody to Staller, but his legal strategies, both alarmingly hypocritical and brilliant, played directly into the fears persistent in this country that pornography is a danger to society, that-unlike "erotica"-it is an anthropomorphic entity actively seeking the ruination of the Christian and the innocent, despite arguments made to the contrary by both feminist anticensorship scholars, such as Laura Kipnis, and pornographic performers who have argued that both conservative and feminist attacks on pornography have allowed porn to assume the role of a scapegoat for real social problems.

Indeed, in light of the Made in Heaven series, one is easily led to doubt 
Koons' sincerity at the custody trial. It seems quite unlikely for example that he could really be as concerned with "Protestant values" and "cultural mores" as he claimed to be under oath. Yet in order to serve his purposes, Koons ultimately allowed himself to become a part of the mechanism of "guilt and shame"- that for Royalle and her colleagues is the real enemy.

\section{Works Cited:}

Arena, Salvatore. "Italian porn star/politician, N.Y. artist in child custody battle." New York Daily News 30 Dec 1993.

“Art or Commerce." Vanity Fair Nov 1991.

Caldwell, John. "Jeff Koons: The Way We Live Now.” Jeff Koons. San Francisco: San Francisco Museum of Modern Art, 1992.

Chapkis, Wendy. Live Sex Acts: Women Performing Erotic Labor. New York: Routledge, 1997.

Danto, Arthur C. "The 1989 Whitney Biennial.” The Nation 5 June 1989.

Foucault, Michel. The History of Sexuality, Volume I: An Introduction. Translated by Robert Hurley. New York: Vintage Books, 1990.

"In a naked play for power, porn queen Cicciolina wins a seat in Italy's Parliament." People Weekly 6 July 87.

Jeff Koons. Cologne: Taschen, 1992.

Jeff Koons. San Francisco: San Francisco Museum of Modern Art, 1992.

Jeff Koons. London: Audio Arts, 1990 [audio recording].

Kipnis, Laura. Bound and Gagged: Pornography and the Politics of Fantasy in America. New York: Grove Press, 1996.

"Koons Crazy." Vogue Aug 1990.

Lee, Andrea. "Letter From Rome." The New Yorker 9 Nov 87.

Lewis, Jim. "A Modest Proposal." Jeff Koons. San Francisco: San Francisco Museum of Modern Art, 1992.

Lilla, Mark. "The Body Politic." The New Republic 28 Sept 87.

Littlejohn, David. "Who is Jeff Koons and why are people saying such terrible things about him?" ARTnews April 1993.

Renton, Andrew. "Jeff Koons: I Have my Finger on the Eternal." FlashArt Summer 1990.

Rosenblum, Robert. The Jeff Koons Handbook. New York: Rizzoli, 1992.

Royalle, Candida. "Porn in the USA." Social Text 37 Winter 1993.

Salvioni, Daniela. "Jeff Koons's Poetics of Class." Jeff Koons. San Francisco: San Francisco Museum of Modern Art, 1992.

"Scenes from a Marriage." The New Yorker 19 Dec 94.

Sprinkle, Annie. "Hard Core Heaven: Unsafe Sex with Jeff Koons." Arts Magazine March 1992.

Van Proyen, Mark. "Puppy Love: Jeff Koons at the San Francisco Museum of Modern Art." Artweek 21 Jan 1993.

Williams, Linda. Hard Core: Power, Pleasure, and the "Frenzy of the Visible." Berkeley, Los Angeles: University of California Press, 1989. 